\title{
The Socratic Method of Instruction: An Experience With a Reading Comprehension Course
}

\author{
Rachid Acim \\ Ibn Zohr University
}

Moroccan teachers of English have tried several pedagogical techniques for teaching English at a higher level. Attention to critical thinking and questioning are still lacking. The Socratic seminar has proven to be a powerful strategy for promoting these two skills. In this article, its applicability to reading comprehension and précis course is reconsidered. Instead of simply being given information, students are forced to gain knowledge through conversation and Socratic dialogue. They are taught to look at the world from different perspectives, to accept differences and maintain esteem for others. Drawing on an observational study, I unveil the pros and cons of the Socratic seminar and report students' impressions of it, along with some recommendations for its usage in Moroccan higher education.

Keywords: the Socratic seminar, Moroccan classroom, critical thinking, reading comprehension course, observation

\section{Introduction}

To know is to know that you know nothing. That is the meaning of true knowledge.

- Socrates

One of the most important reasons to address the Socratic method with its seminar in a higher level Moroccan English classroom is that higher education in Morocco, much like neighboring countries in North Africa, does not provide students with the appropriate skills that are important in today's labor market. Students often complain about the poor classroom environments in the high schools, which, tellingly, do not promote critical thinking and active participation (Gross \& Davies, 2015, p. 146). Thus, it is urgent that university teachers encourage critical thinking and active participation in class: Society needs productive citizens who are competent to make sound judgments and firm decisions. It also needs citizens who are capable of thinking creatively and operating effectively.

Critical thinking skills (CTS), such as questioning, arguing, and inferencing, benefit people socially and educationally, because students belong to a world that is complex, and the problems they will face are complicated (Hirose, 1992). Tense relations among nations, population growth, terror, and armed conflicts, among innumerable other issues, need to be addressed by individuals who are reflective and critical. Developing critical reading and thinking skills, listening and debating skills, public speaking skills, autonomous learning skills, and self-confidence are all valid reasons for including the Socratic method in the Moroccan classroom. However, preparing students for this complex world, where competitiveness and intellectual development are higher, requires serious educational reforms in the Moroccan setting; it requires altering certain methods of teaching, for example, by enhancing students' CTS, along with their reasoning, questioning, and debating abilities. 
CTS should become an important component of English language teaching in Moroccan university classrooms because it help students synthesize their opinions, analyze topics, and evaluate solutions (Çekin, 2015, p. 159). Kincheloe and Weil (2004) presumed that universities should "not only teach the thinking skills themselves but also develop the attitudes and dispositions that assure that these skills will be used" (p. 86). The Socratic seminar is arguably the most convenient way to engender critical thinking among Moroccan students and to guarantee good performance in the learning process.

In this article, I explore the Socratic method of teaching as a disciplined, systematic form of argumentative questioning. This method could be used in the Moroccan English classroom because it is more likely to stimulate critical thinking in students. I assumed that university students in general have been exposed to different opinions, people, and products and then need to examine whether they are capable of thinking critically or not. Critical thinking is not a natural ability, but "must be taught across all subjects and all grade levels" (Orlich et al., 2008, p. 279). It has become a pressing necessity in higher education (Paulsen, 2015).

In the first section, I provide a theoretical background for the study, elaborate on the importance of the Socratic seminar in the context of a reading comprehension and précis course, recommend some pedagogical applications, and describe the limitations of this method of teaching.

\section{Theoretical Background}

The intellectual roots of questioning, reasoning, and critical thinking can be traced to Socrates (469399 BCE), 2,500 years ago (Abelman \& Atkin, 2011, p. 3). This illustrious thinker urged his students to question and think critically about both commonsense beliefs and established facts. When teachers encourage students not to take things for granted, they are using the Socratic method in their teaching by planting the seeds of critical thought into students' minds. Enthusiastic proponents for this method claim that it bears a strong relationship with the style of reasoning required by lawyers and that it is healthy in large classrooms. This is why the Socratic method has been traditionally considered to be at the heart of legal pedagogy.

In fact, no fixed definition of the Socratic method has been provided so far because it is flexible. Any teacher can use it for a particular pedagogical purpose. Here are some widely circulated definitions in academia:

- The Socratic method begins with the assumption that the function of education is to draw the truth out of the pupil rather than "fill an empty vessel." In practice, it is a series of guided questions known as the dialectical method of inquiry. (Soccio, 2015, p. 10, italics in original)

- $\quad[\mathrm{It}]$ has come to mean any pedagogy conducted through question and answer, as distinguished from pedagogy conducted in lecture form. (Scott, 2012, p. 1)

- Any philosophical or pedagogical method that disinterestedly pursues truth through analytical discussion. (Spencer \& Millson-Martula, 2009, p. 39)

According to Reich (2003), who adopted the Socratic method, the instructor is not the purveyor of knowledge, that is, the one who communicates facts and truths to a body of passive students after years of study. The instructor is not "the sage on the stage," but she or he, like the students, is another participant in the building of knowledge. Thus, teachers are accountable for guiding students to a "deeper and clarified consideration of the ideas of the text, a respect for varying points of view, and adherence to and respect for the seminar process" (Tredway, 1995, p. 28). What is interesting about the Socratic method is not only its tendency to question but also its strong capacity to help students differentiate reasonable arguments from unreasonable or ill-formed ones. Copeland 
(2005) posited that it is crucial for the instructor to clarify that frequent questioning in the seminar is not meant to create an environment of judgment, but rather to help students examine their attitudes and beliefs.

Teaching through the Socratic method differs from the expository or formal lecture-style instruction in three ways. First, the Socratic method does not involve the instructor bringing a body of expert knowledge to impart to students.

In [Plato's] Theaetus, Socrates compares the instructor's role to that of a midwife, the instructor helps the student through the process, but it is the student who gives birth to knowledge. Second, the learning that takes place via the Socratic method involves the shedding of false knowledge, rather than adding correct knowledge. Third, there are no preexisting 'correct' answers to Socratic questions. (Spencer \& Millson-Martula, 2009, p. 40)

Socrates used this method to direct people to truth. He performed his mission through frequent and systematic questioning, in the course of which he made his opponents perceive their deficiencies and weaknesses. He was particularly keen on forging logical thinking based on inference.

For the Socratic method to be successful as a didactic technique, teachers need to design what is called the Socratic seminar. Because the teacher's role is primarily that of a designer and facilitator, the ultimate success of the seminar is contingent on the work of the students. "Whatever text is chosen, students are expected to come to class prepared to closely examine the text" (Johnson, 2003, p. 33) and get the most out of it.

The objective of the Socratic seminar is to help students think for themselves and value their own questions. Their focus, unlike other methods of learning, falls on the text in question. The seminar trains their mental and thinking skills and engages them in a rigorous intellectual exercise with no interference from the teacher.

\section{Methodology}

In this study, I drew on systematic observation to measure the engagement of the students in the reading comprehension course while applying the Socratic seminar. Observation is frequently used in research that employs both quantitative and qualitative methods. Research is qualitative when observations are taken to get the full picture of a certain situation. The product of these observations can be either notes or narratives. The goal of this observational study was then to determine the extent to which students are content with the Socratic seminar, whether or not they engaged with it, and most significantly, whether they could exchange knowledge critically, respectfully, and openmindedly via this teaching method. Observation, as noted by McKernan (1991), "is the fundamental basis of educational research" (p. 57). It has two important advantages. First, the use of observation guarantees the recording of behavior as it occurs. Second, it allows the observer to compare what people actually did with what they said they did.

During the teaching experience, I functioned like a camera, cataloguing in a notebook the pros and cons of the method. To let the dialogue run with their peers with complete fluidity, I concentrated on the students' linguistic and nonlinguistic behavior as well as on their performance in the Socratic seminar-their reactions to the questions and their shaping of other questions. The experience, which involved 40 students, passed through three stages: the preparation stage, in which students read the text and answered comprehension questions; the production stage, in which students interacted with each other through questions; and the evaluation stage, in which students reflected on the whole experience. Students were enlightened by Paul's (1993) 6-point taxonomy of Socratic questioning: asking and answering clarifying questions, asking questions that probe assumptions 
and evidence, asking questions about other viewpoints and perspectives, asking questions about implications and consequences, and even asking questions about questions (Knaus, 2006, p. 89). This helped them understand how to pose their questions and how to avoid any potential confusion during the Socratic seminar.

\section{Analysis and Discussion}

This study is based on my teaching experience of a reading comprehension and précis course at Ibn Zohr University in Agadir, Morocco. I taught the course to first-year students (Semester 1), and helped them master the basic skills of reading comprehension, such as searching for the main idea, paraphrasing, summarizing, synthesizing, and so forth. The 2 -hr coeducational class comprised about 60 students.

Routinely, I would distribute reading texts to be prepared for the following week, and I ensured that a variety of topics was addressed and discussed in those texts. Upon noticing the weak involvement of most students, I resolved to extend the course by employing the Socratic seminar format. Put differently, I tried to enhance students' CTS using the Socratic method. The objective was to turn students from passive consumers of the reading into active, critical readers.

The exercise started with a text titled "The Socratic Wisdom" by Socrates (see Bhasker \& Prabhu, 1975, p. 131). Students were asked to read through the text at home, answer comprehension questions, look up complex terms, paraphrase certain statements as usual, draw inferences, and eventually produce a précis of it. But they had to think Socratically later. At first, students were perplexed because they had never been exposed to this method of learning before. However, they demonstrated a high level of motivation and curiosity to explore it.

xAs an activity, a Socratic seminar took place in a traditional classroom with desks and chairs rearranged in two concentric circles: an inner and outer one. Each participant in the inner circle, seated in a "hot seat," was assigned a coach from the outer circle. A few students were reluctant to take part. I authorized an informal 5-min discussion between participants of either gender to build up a sense of collaboration and trust before the seminar started. A group of 10 female students faced 10 male students in the inner circle, while 20 male and female coaches observed the participants' performance and evaluated objectively their speaking and CTS based on an observation form. Students in both circles were invited to extract a topic from the reading text cited above to be debated in a disciplined and thoughtful dialogue. Figure 1 illustrates the format of the seminar that was used in the reading comprehension and précis class.

A rough list that subsumes topics such as truth, wisdom, politics, knowledge, and ignorance was formed. Then, after voting, consensus was achieved with ignorance as the central topic. One participant posed the open-ended question: What is ignorance? As Fisher and Frey (2007) put it, "The [Socratic] question should have no right answer. Instead, the question should reflect authentic wonder and interest” (p. 59). 


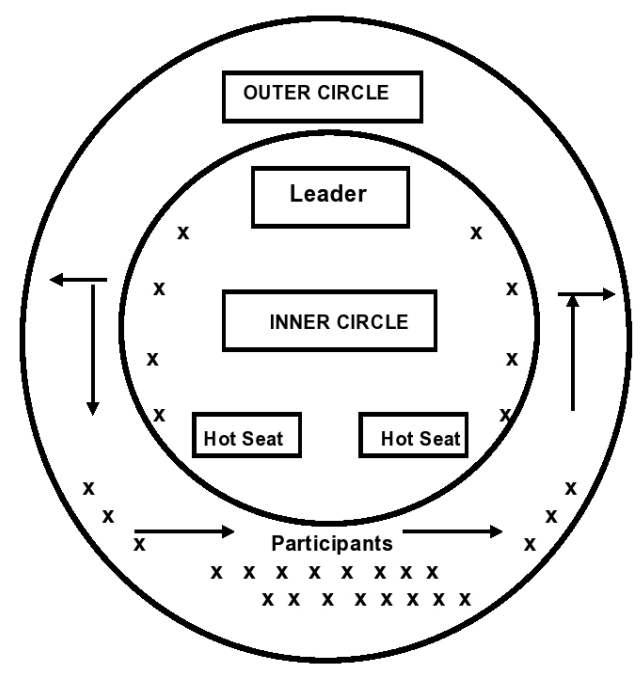

Figure 1. Inner and Outer Circle in the Socratic Seminar

As the leader of the seminar, I reminded participants that all voices should be heard and that they had to comply with the guidelines. Here is a list of some guidelines I gave participants for the Socratic seminar (Easton, 2011, p. 129):

- Refer to the text when necessary.

- Ask for clarification.

- Do not digress from the topic.

- Take turns speaking.

- Listen carefully.

- Be open to different views.

- Use appropriate language.

- Remember to play your part.

- Be courteous and polite.

Though the participants referred back to the text for more information, the topic was discussed in a surface-level fashion. Some participants got somewhat nervous and stressed in the inner circle of the seminar; others were silent and could not keep up with the pace of the debate. The latter case applied to certain female participants, who generally showed less participation than the males. Whenever the discussion would come to a deadlock, I would help the students of the inner circle with another open-ended question to stimulate more responses and get them back to the basis of the Socratic debate. Here is how a leader might put the questions:

1. What is ignorance?

2. How can you prove that all human beings are ignorant?

3. What is ignorance analogous to?

4. What is another alternative to ignorance?

5. Were the people of Athens ignorant?

6. Why did Socrates believe that politicians and poets were ignorant?

7. Why can you not believe that all mortals are ignorant?

8. Does the lack of knowledge presuppose ignorance?

9. Is knowledge exclusive to humanity or to divinity?

10. What do you think of philosophers like Socrates, Plato, Aristotle, and others? Were they ignorant? 
11. Did modern technology ease the phenomenon of ignorance?

12. Is ignorance genderless?

The students in the inner circle were sometimes unable to structure and develop relevant and probing questions that would be more likely to get them to reflect and react on the spot. Meanwhile, the student coaches in the outer circle were watchful, taking notes on what was happening, writing prompt feedback, evaluating the participants' overall performance, and in the words of Midura and Glover (2005), "guiding the participants to interact meaningfully with their teammates" (p. 24). As the temporary seminar leader, I had to encourage the coaches in advance to be accurate but fair with their peer evaluations. Consider the Appendix, which replicates the observation form handed out to the coaches.

Most of the coaches observed that the participants' talking time was unbalanced because some students were excited enough to monopolize and control the seminar through frequent questioning and interruption. However, the most compelling benefit of the experience was the participants' tendency to reject any answer provided by their peers and the former's strong resolution to think of other plausible, worthwhile questions. Another salient benefit was that the seminar taught students argumentative skills, careful listening, and the importance of verbal and nonverbal discourse. All of this qualified them for the public speaking and debating course for their undergraduate studies in Semester 3.

Although not developed as a course at the university, the seminar, as a one-off instructional strategy, led the students, in this observational study, to think about and reflect on their prior knowledge to reconsider some assumptions that had been taken for granted and see the world from other students' perspectives. Along with Marchesani (2007), I found that the Socratic seminar moved the lesson away from the teacher as a holder of knowledge (the sage on the stage) and toward to the students as individuals who were acquiring the power to think and contribute to knowledge-building in class. The students saw the seminar as a double-edged sword. On the one hand, it allowed them to engage with the text and even go beyond it through critical interaction. On the other hand, it was challenging for them because the process was continuous and the atmosphere was occasionally tense.

Another implication of this observational study is that aside from being confrontational with respect to gender, the seminar was capable of sparking a hot discussion and conducive to forging and reshaping students' critical thinking and logical reasoning skills. Critical thinking is what Moroccan undergraduates are often accused of not doing (Doris, 2013). At the university level, they can neither think deep thoughts nor articulate their opinions systematically because there is no structured university course for that (Maan, 2012). This is confirmed by Chouari (2016), who stated that "in Morocco, critical thinking is a new concern in the field of [university] education" (p. 459), and that no independent course covered critical thinking. At Ibn Zohr University, the helpful Semester 1 undergraduate courses, which students of the English department benefit from, include courses called Reading Comprehension and Précis, Study Skills, Writing Paragraphs, Spoken English, Guided Reading, and Grammar. But CTS are not taught directly in Moroccan undergraduate studies. Sometimes they are addressed in major courses such as Reading Comprehension and Précis or Study Skills.

One point of this observational study was the question of legitimacy: Who was the legitimate speaker in the inner and outer circle? By legitimacy, I mean the person who had the right to direct the seminar and ensure its fluidity. In the experience of the Socratic seminar, legitimacy was located with the leader-the teacher-to whom all participants turned for guidance and direction. The teacher was the observer who gave feedback (Harmer, 2001, p. 6), and he was also the facilitator, who sought "to blend into the group and not be perceived as an authority figure" (Ball \& Brewer, 
2000, p. 21). Much like the coaches of the outer circle, the role of the leader was reduced to that of an observer because he hardly intervened in the Socratic debate. That way, he made the experience natural, smoothly unfolding, and fully student centered.

This pedagogical method was intended to assign responsibility to students in a rigorous and challenging way. The teacher's role, therefore, was simply to provide instructions, to motivate students to take part, and then turn the ball over to them. The Socratic seminar put students at the center of learning. They were led to pose questions and contribute to the discussions. The underlying idea was that students were accountable for their own learning.

\section{Politeness and Gender Clash}

I noted that sometimes, the participants on either side of the inner circle digressed from the central topic to discuss trivia and secondary issues. Whereas prosody and some paralinguistic elements (e.g., body language, facial expressions, posture, etc.) were smartly used by some male participants as a stratagem to dominate the seminar, naiveté was used by others to win the Socratic game. Two male participants used another provocative stratagem when they stood up one at a time and addressed their female "adversaries," saying, "We know nothing. We are ignorant. Please teach us knowledge. Show us true wisdom!" Such daring and an improper linguistic and nonlinguistic behavior, which could have resulted in a gender clash, was simply criticized by one female participant, who reminded the two males to respect the norms and conventions of the seminar. The two males had to defend themselves because they felt themselves incompetent in using good politeness techniques. Males were less organized and less professional than the females.

Female participants, though probably not well informed of Grice's (1999) conversational maxims (e.g. maxim of quantity, maxim of quality, maxim of relation, maxim of manner), did not flout most of these general principles. Instead, these females struggled to be clear, to the point, truthful, informative, and well organized in their critical comments. As opposed to the females, the males were talkative and unquiet. It was remarkable that the females wanted to cooperate with the males to better question "ignorance" because the seminar, as they thought, was forged to enhance their communication abilities and CTS. They were not aspiring to be victorious in the seminar. What is more, they were able to use politeness strategies as they ensured peace and harmony in the Socratic interaction through their great concern for the feelings of the males, their awareness and care for them: They were brief and cooperative. They were neither offensive nor discourteous; rather, they were more tactful and considerate in their interactions with the males. Politeness strategies are used more by women than by men (Wray \& Bloomer, 1998, p. 105). This applied to the female participants, as they did not shout like the males, nor did they infringe on the etiquettes of the seminar; instead, they listened attentively, avoided interrupting, and respected different opinions.

Once the seminar was over, I asked both the coaches and the participants to write down their impressions of the experience. I emphasized that they should address, each from her or his own position, the positive and negative sides. To my amazement, virtually all participants expressed a liking for, and a good appreciation of, the Socratic seminar: It gave them a space where they could think and talk freely, ask and answer rhetorical questions, and interact with each other in a friendly way. Only few students did not like the Socratic seminar. This could be attributed to inadequate debating skills or to an inability to pose questions and air logical arguments. In commenting on the performance of the female participants, a female student wrote, "I do not like girls. They interrupt each other, give incomplete ideas, as opposed to boys, who stick to the topic and respect it." Such derogatory comments are more likely to be irrelevant because many female participants, in the outer circle, were relatively appreciative of the performance of their peers in the inner circle. 
As mentioned earlier, 40 responses were clustered from the participants and their coaches, the majority of whom enjoyed the seminar and judged it both effective and efficient as a follow-up strategy in the reading comprehension and précis course. The following comments make clear that the seminar generally satisfied students' need to think and talk at the same time:

- I liked the experience of the Socratic seminar because I had the opportunity to express my ideas and debate my classmates' opinions, even if it was for 30 minutes. I would like to repeat the same experience again and again.

- The Socratic seminar was really constructive. Not only did it relieve us from stress but also allowed everyone to speak. It should be repeated so that other students could enhance their communication skills.

- Thanks to the Socratic seminar, I could know how others think; besides, this exercise made us more confident and helped us gain courage to speak and "bring out" what we held inside ourselves.

- It was a good experience for everybody. It taught us how to listen, how to be critical and how to respect others' ideas.

- It was a good way of evaluating our ability to defend arguments. As for the negative side, everyone talked at the same time. And sometimes I could not see who was speaking. Participants kept interrupting each other.

- I found the seminar interesting because we were exposed to multiple opinions about the topic "ignorance." However, some students did not participate at all.

The findings of this observational study cannot be generalized because it merely vehicles my own experience with a reading-based course, a course that is subject to several restrictions and constraints such as the large size of the classroom, the time/space factors, and the (un)preparedness of students to undergo the experience of the Socratic seminar. The observational study, likewise, did not report students' anxiety and interest rate vis-à-vis the seminar because the latter was meant to finish a reading activity in a text about Socrates' wisdom and invite all students, with no exception, to practice CTS on a certain textual topic.

The method is flawed because it requires good debating skills, can diminish students' self-confidence, and it can discourage others from participating. However, it teaches students to be "their own best teacher" and to develop a good sense of reasoning before talking. In other terms, students were monitoring their level of anxiety, motivation, and self-efficacy along the learning process. It is believed that logical reasoning is immanent within us (Bergkamp, 2001); only critical thinking is needed to call it forth. This reasoning was the real task of the above Socratic seminar.

\section{How to Implement Socratic Seminars}

Start with a small number of students and start the seminars as 5-min exercises, slowly building up to 30-50 min. Consider using a "fishbowl" approach, in which half the class forms an inner circle to discuss the text and the other half forms an outer circle to observe their peers and critique the discussion, for example, by examining their communication skills and their capacity to argue and to launch critical questions.

Choose a simple text. First and foremost, the students must carefully read the text. They must take notes, mark up the text, design potential questions, and get ready for the Socratic discussion. The seminar will be a fiasco if the students have not prepared the text beforehand. Students should be directed to make sense of the text, interpret it, analyze it, and then critique it.

Next, the leader of the seminar-whether the teacher or a student-should give instructions about the structure and the evolution of the seminar, how it operates, and why it should work this way and 
not other ways. Then, opening questions or provocations related to the text need to be developed to encourage students to participate and then take the initiative. In the case of a story, for instance, the seminar leader might start by saying, "I'm confused about its theme. Can anyone help me understand it better?" Or, in using something like the periodic table, they might pose the following question: "Why do we need to organize the elements this way? What are the advantages and disadvantages of this system?" (Johnson, 2003, p. 43). In all cases, the role of the leader is to initiate, not monopolize, the discussion.

Finally, the entire class-even those who did not participate-should be invited to evaluate the whole experience of the Socratic seminar. Deep reflection on the experience, including its weaknesses and strengths, would help students learn from their mistakes and advance more rapidly in any upcoming seminar. Using the Socratic seminar in a reading comprehension course maybe a fruitful avenue for promoting CTS in Moroccan higher education. In fact, it is capable of stimulating students' thoughts and directing them to critically examine their common ground knowledge in different subjects. Its application is then becoming a necessity in Moroccan higher education because it engages students in intellectual rigor and polishes their communication skills to operate effectively within the global English language market.

\section{Conclusion}

The Socratic seminar is the preeminent approach to critical thinking. Besides providing students with an arena in which to test their self-confidence as critical readers, thinkers, and speakers, it serves students as an eye-opener for seeing the world from different perspectives. It urges them to think deeply through questioning and intellectual analysis, to listen carefully to others, and to avoid taking their statements at face value. Although the Socratic seminar could be challenging, continuous practice guarantees success. The role of the teacher should be limited to that of an observer and facilitator, documenting the participants' successes and failures and thinking about ways to improve the Socratic seminar in the future. Applying the Socratic seminar, in Moroccan and non-Moroccan educational contexts, is highly recommended, as it can create active learners by engaging them in the exploration and evaluation of novel ideas. Its efficiency, therefore, goes beyond the reading comprehension course to include other areas such as science, literature, law, and social sciences and, perhaps most significant of all, caters to the needs of learners of all levels and sociocultural backgrounds.

\section{References}

Abelman, R., \& Atkin, D. J. (2011). The televiewing audience: The art and science of watching TV. New York, NY: Peter Lang Publishing.

Ball, W. B., \& Brewer, P. (2000). Socratic seminars in the block. New York, NY: Eye on Education.

Bergkamp, L. (2001). Liability and environment: Private and public law aspect of civil liability for environmental harm in an international context. The Hague, The Netherlands: Kluwer International.

Bhasker, W. S., \& Prabhu, N. S. (1975). English through reading. Hong Kong: Macmillan.

Çekin, A. (2015). The investigation of critical thinking dispositions of religious culture and ethics teacher candidates (The case of Ankara University and Kastamonu University in Turkey). Journal of Education and Learning, 9, 158-164.

Chouari, A. (2016). Teaching critical thinking in Moroccan higher education: Challenges and opportunities. Arab World English Journal, 7, 459. 
Copeland, M. (2005). Socratic circles: Fostering critical and creative thinking. Portland, ME: Stenhouse Publishers.

Doris, G. (2013). Beyond feminisms and Islamism: Gender and equality in North Africa. London, United Kingdom: Tauris.

Easton, L. B. (2011). Professional learning communities by design: Putting the learning back into PLCs. Ventura, CA: Corwin.

Fisher, D., \& Frey, N. (2007). Checking for understanding: Formative assessment techniques for your classroom. Alexandria, VA: The Association for Supervision and Curriculum Development.

Grice, P. H. (1999). Logic and conversation. In A. Jaworski \& N. Coupland (Eds.), The discourse reader (pp. 76-88). London, United Kingdom: Routledge.

Gross, Z., \& Davies, L. (2015). The contested role of education in conflict and fragility. Rotterdam, The Netherlands: Sense Publishers. Retrieved from https://www.sensepublishers.com/media/2332-the-contested-role-of-education-in-conflict-andfragility.pdf

Harmer, J. (2001). The practice of English language. Kuala Lumpur, Malaysia: Pearson Education.

Hirose, S. (1992). Critical thinking in community colleges. Retrieved from http://ericae.net/edo/ed348128.htm

Johnson, B. (2003). The student-centered classroom handbook: A guide to implementation. New York, NY: Routledge.

Kincheloe, J. L., \& Weil, D. K. (2004). Critical thinking and learning: An encyclopedia for parents and teachers. London, United Kingdom: Greenwood Press.

Knaus, W. J. (2006). Cognitive behavioral workbook for depression: A step-by-step program. Oakland, CA: New Harbinger Publications.

Maan, N.A. (2012). Critical thinking and the Moroccan educational context. Retrieved from http://search.shamaa.org/PDF/Articles/MOAmm/AmmNo4-5Y2012/amm_2012-n4-5_026048_eng.pdf

Marchesani, R. (2007). The field guide to teaching: A handbook for new teachers. Upper Saddle River, NJ: Pearson Merrill Prentice Hall.

McKernan, J. (1991). Curriculum action research: A handbook of methods and resources for the reflective practitioner. London, United Kingdom: Kogan Page.

Midura, D. W., \& Glover, D. R. (2005). Essentials of team building: Principles and practices. Champaign, IL: Human Kinetics.

Orlich, D. C., Harder, R. J., Callahan, R. C., Trevisan, M. S., Brown, A. H., \& Miller, D. E. (2008). Teaching strategies: A guide to effective instruction. Boston, MA: Wadsworth, Cengage Learning.

Paul, R. (1993). Critical thinking: What every person needs to survive in a rapidly changing world. Santa Rosa, CA: Foundation for Critical Thinking.

Paulsen, M. B. (2015). Higher education: Handbook of theory and research. Des Moines, IA: Springer,

Reich, R. (2003, Fall). The Socratic method: What it is and how to use it in the classroom. Speaking of Teaching, 13, 1-4. Retrieved from https://web.stanford.edu/dept/CTL/Newsletter/socratic_method.pdf

Scott, G. A. (2012). Does Socrates have a method? Rethinking Elenchus in Plato's dialogues and beyond. Philadelphia, PA: The Pennsylvania State University. 
Soccio, D. J. (2015). Archetypes of wisdom: An introduction to philosophy. Boston, MA: Cengage Learning.

Spencer, S., \& Millson-Martula, C. (2009). Critical thinking with the library program. New York, NY: Routledge.

Tredway, L. (1995, September). Socratic seminars: Engaging students in intellectual discourse. Educational leadership, 53, 26-29.

Wray, A., \& Bloomer, A. (1998). Projects in linguistics and language studies. New York, NY: Routledge.

Zepeda, S. J., \& Mayers, R. S. (2013). Supervision across the content areas. New York, NY: Routledge.

[Appendix follows] 


\section{Appendix}

\section{Coaches' Observation Form}

\section{Coach:}

Participant:

Instructions: Each time your partner does one of the following, tick one of the boxes below.

Asks a question

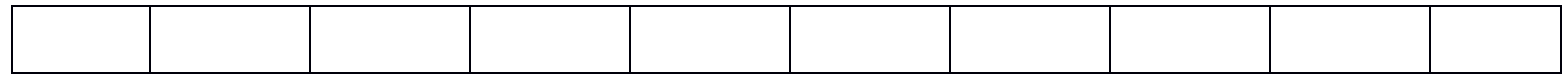

Answers a question

\begin{tabular}{|l|l|l|l|l|l|l|l|l|l|}
\hline & & & & & & & & & \\
\hline
\end{tabular}

Refers to the text

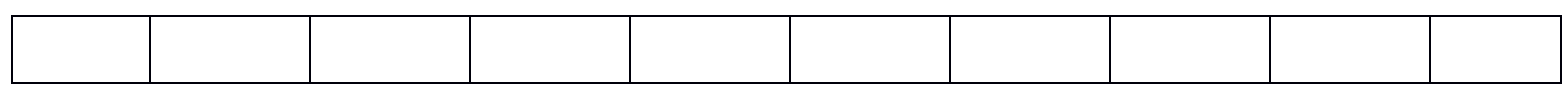

Listens attentively

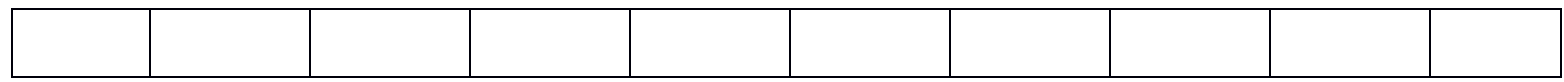

Advances a logical argument

\begin{tabular}{|l|l|l|l|l|l|l|l|l|l|}
\hline & & & & & & & & & \\
\hline
\end{tabular}

Interrupts another participant

\begin{tabular}{|l|l|l|l|l|l|l|l|l|l|}
\hline & & & & & & & & & \\
\hline
\end{tabular}

Uses body language

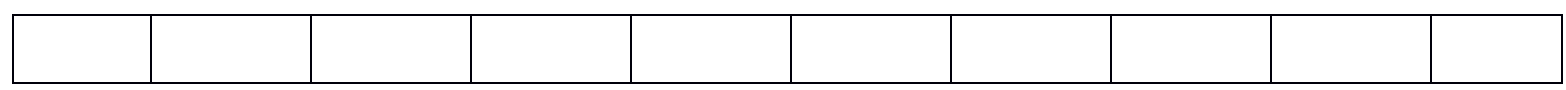

Respects opinions

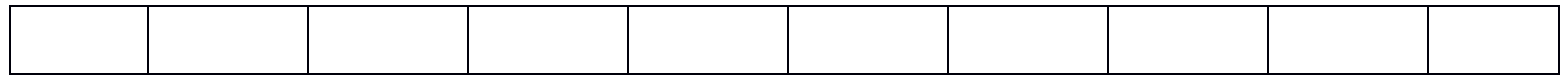

Gives other remarks

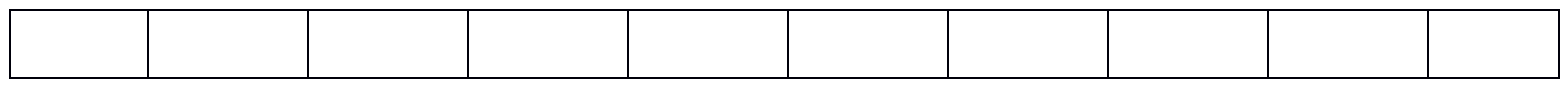

Note: Adapted from Zepeda and Mayers (2013, pp. 158-159). 
The Journal of Educational Research and Practice provides a forum for studies and dialogue that allows readers to better develop social change in the field of education and learning. Journal content may focus on educational issues of all ages and in all settings. It also presents peer-reviewed commentaries, book reviews, interviews of prominent individuals, and additional content. The objectives: We publish research and related content that examines current relevant educational issues and processes aimed at presenting readers with knowledge and showing how that knowledge can be used to impact social change in educational or learning environments. Additional content provides an opportunity for scholarly and professional dialogue regarding that content's usefulness in expanding the body of scholarly knowledge and increasing readers' effectiveness as educators. The journal also focuses on facilitating the activities of both researcher-practitioners and practitioner-researchers, providing optimal opportunities for interdisciplinary and collaborative thought through blogging and other communications.

Walden University Publishing: http://www.publishing.waldenu.edu 